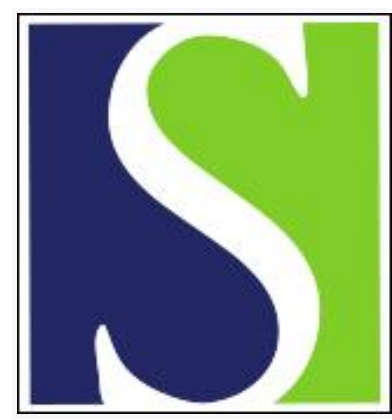

Scand J Work Environ Health 2009;35(6):429-436

https://doi.org/10.5271/sjweh.1353

Published online: 01 Oct 2009, Issue date: 00 Dec 2009

Socioeconomic position and low-back pain - the role of biomechanical strains and psychosocial work factors in the GAZEL cohort

by Plouvier S, Leclerc A, Chastang J-F, Bonenfant S, Goldberg M

Affiliation: INSERM U687, 16 Avenue Paul Vaillant-Couturier, 94804 Villejuif Cedex, France. sandrine.plouvier@inserm.fr

Refers to the following texts of the Journal: 2005;31(6):409-437

2008;34(4):260-266 1997;23(4):243-256 2008;34(4):250-259

$2008 ; 34(4): 235-238$

The following article refers to this text: $2014 ; 40(1): 1-3$

Key terms: biomechanical strain; GAZEL cohort; health inequality; low-back pain; MSD; musculoskeletal disorder; occupational exposure; psychosocial factor; psychosocial work factor; social inequality; socioeconomic position; socioeconomic status; work factor

This article in PubMed: www.ncbi.nlm.nih.gov/pubmed/19806277 


\title{
Socioeconomic position and low-back pain - the role of biomechanical strains and psychosocial work factors in the GAZEL cohort
}

\author{
by Sandrine Plouvier, MD, ${ }^{1}$ Annette Leclerc, PhD, ${ }^{1}$ Jean-François Chastang, PhD, ${ }^{1}$ Sébastien Bonenfant, \\ $M S,{ }^{1}$ Marcel Goldberg, $M D, P h D^{1}$
}

\begin{abstract}
Plouvier S, Leclerc A, Chastang J-F, Bonenfant S, Goldberg M. Socioeconomic position and low-back pain - the role of biomechanical strains and psychosocial work factors in the GAZEL cohort. Scand J Work Environ Health. 2009;35(6):429-436.
\end{abstract}

Objective To analyze the role that biomechanical strains and psychosocial work factors play in occupational
class disparities in low-back pain in the GAZEL cohort.
Methods Recruited in 1989, the GAZEL cohort members were employees of the French national company in
charge of energy who volunteered to enroll in an annual follow-up survey. The study population comprised 1487
men who completed questionnaires in 1996 (past occupational exposure to manual material handling, bending/
twisting, and driving), 1997 (psychosocial work factors), and 2001 (low-back pain using a French version of the
Nordic questionnaire for the assessment of low-back pain). Associations between low-back pain for $>30$ days
in the preceding 12 months and social position at baseline (four categories) were described with a Cox model
to determine prevalence ratios for each category. We compared adjusted and unadjusted ratios to quantify the
contribution of occupational exposures.

Results The prevalence of low-back pain for $>30$ days was $13.6 \%$. The prevalence of low-back pain adjusted for age was significantly higher for blue-collar workers and clerks than for managers. The number of socioeconomic disparities observed was significantly reduced when biomechanical strains were taken into account; adjusting for psychosocial factors had little impact.

Conclusion In this population, occupational exposures - especially biomechanical strains - played an important role in occupational class disparities for persistent or recurrent low-back pain.

Key terms health inequality; musculoskeletal disorder; occupational exposure; social inequality; socioeconomic status.

For most health dimensions, health status is worse in lower socioeconomic groups. Such socioeconomic disparities have been described for back pain in several studies (1-4). Many factors vary between groups according to socioeconomic position and may thus contribute to social inequalities in health; these can include early life circumstances, lifestyle, the physical and psychosocial environment, employment, and working conditions $(5,6)$. Some occupational factors contribute to the association between socioeconomic position and self-rated health in cross-sectional studies (7-13), and the social gradient in the deterioration in self-rated health over one year (12) and five years (14). Other studies have looked at the contribution of working conditions to social inequalities in depressive symptoms, physical function- ing (15), longstanding illness (11), and the incidence of coronary heart disease (16) for instance.

A few studies have indicated that occupational factors contribute to socioeconomic disparities in musculoskeletal disorders in general $(8,17-19)$. Physical and psychosocial work characteristics accounted for a substantial part of the relation between socioeconomic status and musculoskeletal complaints in men who graduated from high school in Wisconsin (8). Physical demand at work explained a large part of occupational class disparities in musculoskeletal disorders for employees of the city of Helsinki (17). In a study of a working population in France (the Pays de la Loire study), physical occupational factors accounted for more than $50 \%$ of the disparities between manual and

1 Institut National de la Santé et de la Recherche Médicale (INSERM) [National Institute of Health and Medical Research], U687-IFR69, Hôpital Paul Brousse, Villejuif, France.

Correspondence to: Sandrine Plouvier, INSERM U687, 16 Avenue Paul Vaillant-Couturier, 94804 Villejuif Cedex, France. [E-mail: sandrine. plouvier@inserm.fr] 
non-manual workers for upper-limb disorders (18). In the general working population of Oslo, physical job demands and job autonomy explained a substantial portion of occupational class disparities in musculoskeletal complaints (19).

Physical exposures at work (eg, bending, twisting, manual material handling, and whole body vibrations) are considered to be risk factors for low-back pain $(20,21)$; psychosocial factors at work are also reported to play a role $(22,23)$. These types of factors might, therefore, explain at least a part of the social inequalities in low-back pain. This question has not been examined in detail, and conclusions from the studies on this topic appear somewhat conflicting. In Oslo, working exposures, especially physical job demands, accounted for a substantial portion of the absolute inequalities between occupational classes for low-back pain (19). In a population-based survey in France, the association between education and low-back pain was also mainly mediated by physical factors at work (24), while a study in Germany was unable to explain the relation between education and severe back pain by occupational factors (25).

Our hypothesis in this study was that low-back pain is associated with socioeconomic position, and occupational exposures are a pathway for this relation. More precisely, we sought to assess the relations between low-back pain in the longitudinal GAZEL cohort and socioeconomic position (measured by occupational category or class), and analyze the contribution of biomechanical strains and psychosocial work factors to these relations.

\section{Materials and methods}

\section{Population and study design}

The GAZEL cohort was established in 1989. Its members were recruited among the employees of Electricité de France-Gaz de France, the French national company for the production and distribution of energy $(26,27)$. At that time, the company employed approximately
150000 people of diversified trades and socioeconomic categories, with civil servant-like status throughout France. At baseline in 1989, the cohort included 20624 volunteers, men then aged 40-50 years and women 3550 years. In January of each year, participants receive a general questionnaire about their lifestyle, health, and occupational situation. Specific themes, such as lowback pain, are also explored.

The population for our study came from the population selected for the "GAZEL low-back pain" sub-project (28), which included 4018 cohort members, 3377 of whom were men. These members were randomly selected from occupational groups in which at least $20 \%$ of workers were exposed to selected occupational strains related to postures, vibrations, manual material handling, and video display terminals. This sample received specific questionnaires on low-back pain in 1992, 1994, and 1996. Our study population comprised the men who completed the 1996 low-back pain questionnaire, the 1996 and 2001 general questionnaires $(\mathrm{N}=2218)$, and the 1997 questionnaire on psychosocial factors at work. We therefore analyzed 1487 men (44\%).

We analyzed information on: (i) socioeconomic position recorded in 1989, (ii) personal data and occupational history assessed in 1996, (iii) psychosocial factors at work compiled in 1997, and (iv) low-back pain selfassessed in 2001 (figure 1).

\section{Socioeconomic position}

Data on socioeconomic position at baseline (1989) were extracted from corporate files and coded according to the French national classification of occupations and socioeconomic categories (PCS). Four categories were used: (i) managers and higher intellectual professions, (ii) intermediate professions (eg, technicians, foremen, supervisors, teachers), (iii) clerks, and (iv) blue-collar workers.

\section{Low-back pain}

The 2001 general questionnaire collected information about low-back pain with questions derived from the Nordic questionnaire for the analysis of musculoskeletal

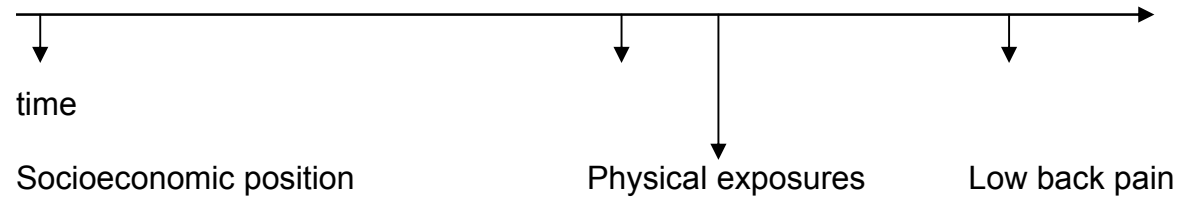


symptoms (29). Low-back pain was defined by reference to a diagram of the body: "pain, discomfort or disability in this area, whether or not the pain radiates to the leg". Subjects reported the cumulative duration of low-back pain during the previous 12 months (ie, 0 days, $\leq 7$ days, 8-30 days, $>30$ days but not every day, or every day). The outcome of interest in the study was low-back pain that lasted $>30$ days, which is generally considered to be frequent or long-lasting pain (30).

\section{Biomechanical strains}

In the 1996 specific questionnaire, cohort members reported their cumulative duration of exposure during their working life to three biomechanical strains: (i) driving a car for $>2$ hours/day; (ii) usually pushing, pulling, or carrying heavy loads (at least once a week); and (iii) bending (forward/backward) or twisting repeatedly, daily or almost daily. Four answers were possible for each exposure (ie, never, $<10$ years, 10-20 years, $>20$ years).

\section{Psychosocial factors at work}

In the general 1997 questionnaire, psychosocial factors at work were assessed with a French version of the Karasek Job Content Questionnaire (31, 32). Respondents had to state the extent to which they agreed with each item (ie, completely agree, agree, do not agree, do not agree at all); a score was calculated for each of the three dimensions: (i) psychological demand (9 items), (ii) decision latitude (9 items), and (iii) social support received from coworkers and superiors (8 items).

\section{Analyses}

Relations between low-back pain in 2001 and socioeconomic position in 1989 were first assessed with Chi-square tests. We also verified that the occupational exposures studied were distributed differently across socioeconomic groups.

Thereafter, we used Cox regression models with a constant risk period (one year) assigned to everyone to obtain a prevalence ratio (PR) of low-back pain for each socioeconomic group compared with managers. Cox models were preferred to logistic regression models, because PR are easier to interpret than odds ratios, especially for rather common diseases (33). Robust variance estimates were used to calculate the confidence intervals (34).

In accordance with previous analyses, the duration of exposure was considered a quantitative variable (35). Each potential answer in the questionnaire, proposed as a category, was replaced by the value of its class center (ie, never $=0,<10$ years $=5,10-20$ years $=15$, and $>20$ years $=25)$. For each psychosocial scale, scores were dichotomized at the median of their distribution in the population. Age (in 1996) was forced into the models.

In a first set of analyses, we constructed age-adjusted models to study the associations between low-back pain and socioeconomic position, and between low-back pain and each occupational exposure, separately. Only the occupational factors associated with low-back pain at $\mathrm{P}$-value $<0.20$ were kept for the subsequent models (models A, B, and C). In the initial model (model A), the age-adjusted association between low-back pain and socioeconomic position was further adjusted for the relevant biomechanical strains. In the second model (model B), the age-adjusted association between low-back pain and socioeconomic position was further adjusted for the relevant psychosocial factors. In the final model (model C), the age-adjusted association between low-back pain and socioeconomic position was adjusted for both the relevant biomechanical and psychosocial factors (those included in model A or B).

In each of these three models, we estimated the contribution of the occupational factors in the model (biomechanical strains, psychosocial factors, or both) to the association between low-back pain and socioeconomic position by comparing the PR of low-back pain for a defined socioeconomic position (adjusted and not adjusted for these factors) as follows $(36,37)$ :

(PR partly adjusted $-P R$ further adjusted for the factors added in the model) / (PR partly adjusted - 1)

We calculated confidence intervals for the contribution of occupational factors by bootstrap (38).

\section{Results}

\section{Low-back pain and socioeconomic position}

Intermediate grade was the most common socioeconomic position; there were few clerks among these male cohort members. The one-year prevalence of low-back pain for $>30$ days was $13.6 \%$ in the overall study population (table 1). A gradient in the prevalence of low-back pain was observed, with the smallest prevalence for the highest socioeconomic position ( $\mathrm{P}$-value for trend $<0.0001$ ). However, prevalence was rather similar in the two first categories, namely, managers and intermediate professions.

\section{Socioeconomic position and occupational strains}

Durations of exposure to biomechanical strains (given only for $\geq 10$ years in table 1 ) varied according to socioeconomic position. Globally, the higher the socioeconomic position, the higher the percentage of 
Table 1. Low-back pain for $>30$ days and occupational strains according to socioeconomic position in the study population.

\begin{tabular}{|c|c|c|c|c|c|c|c|c|c|c|}
\hline & \multicolumn{2}{|c|}{$\begin{array}{l}\text { Study population } \\
\qquad(\mathrm{N}=1487)\end{array}$} & \multicolumn{2}{|c|}{$\begin{array}{l}\text { Managers } \\
(\mathrm{N}=464)\end{array}$} & \multicolumn{2}{|c|}{$\begin{array}{l}\text { Intermediate grade } \\
\qquad(\mathrm{N}=590)\end{array}$} & \multicolumn{2}{|c|}{$\begin{array}{l}\text { Clerks } \\
(\mathrm{N}=61)\end{array}$} & \multicolumn{2}{|c|}{$\begin{array}{l}\text { Blue-collar workers } \\
\qquad(\mathrm{N}=372)\end{array}$} \\
\hline & $\mathrm{N}$ & $\%$ & $\mathrm{~N}$ & $\%$ & $\mathrm{~N}$ & $\%$ & $\mathrm{~N}$ & $\%$ & $\mathrm{~N}$ & $\%$ \\
\hline Low-back pain $>30$ days & 202 & 13. 6 & 48 & 10.3 & 64 & 10.85 & 15 & 24.6 & 75 & 20.2 \\
\hline Driving $\geq 10$ years & 601 & 40.4 & 64 & 13.8 & 232 & 39.3 & 30 & 49.2 & 275 & 73.9 \\
\hline Bending/twisting $\geq 10$ years & 651 & 43.8 & 78 & 16.8 & 254 & 43. 0 & 40 & 65.6 & 279 & 75.0 \\
\hline Handling loads $\geq 10$ years & 430 & 28.9 & 22 & 4.7 & 172 & 29.1 & 17 & 27.9 & 219 & 58.9 \\
\hline High psychological demand & 767 & 51.6 & 312 & 67.2 & 280 & 47.5 & 17 & 27.9 & 158 & 42.5 \\
\hline Low decision latitude & 866 & 58.2 & 160 & 34.5 & 387 & 65.6 & 49 & 80.3 & 270 & 72.6 \\
\hline Low social support & 745 & 50.1 & 209 & 45.4 & 308 & 52.2 & 34 & 55.7 & 194 & 52.1 \\
\hline
\end{tabular}

"never exposed" subjects. Most managers had never been exposed to any of the biomechanical strains studied, while blue-collar workers had often been exposed to them - and for a long time. Bending/twisting and driving for a long time were also rather common for clerks. Psychosocial factors at work also differed according to the socioeconomic position. Managers reported a high level of job demand more often than the others and a low level of decision latitude less often. This latter strain concerned mainly clerks and blue-collar workers. A low level of social support was scarcer among managers than in the other groups.

\section{Low-back pain and occupational strains}

The one-year prevalence of low-back pain increased with the cumulative duration of exposure to each biomechanical strain. It was also always highest for those exposed to a more strenuous level of psychosocial factors at work.

\section{Low-back pain, socioeconomic position, and occupational strains}

The first set of analyses with Cox models, adjusted for age, showed a significantly higher prevalence of lowback pain for blue-collar workers and clerks compared with managers (table 2). Low-back pain was significantly associated with each biomechanical strain and a low level of decision latitude. The association with a low level of social support was on the borderline of significance.

When the association between low-back pain and socioeconomic position was also adjusted for biomechanical strains (model A), the PR for blue-collar workers decreased by $73 \%$ and was no longer significantly different from 1 . For clerks, it decreased by $45 \%$, but prevalence for clerks remained significantly higher than that of managers.

When the age-adjusted association between lowback pain and socioeconomic position was also adjusted for the relevant psychosocial factors - decision latitude and social support (model B) - the PR for blue-collar workers and clerks decreased by $11 \%$ but remained significantly different from 1.

Finally, in the fully adjusted model (model C), the PR for blue-collar workers decreased by $77 \%$, compared with the age-adjusted model, and by $74 \%$ when compared with the model adjusted for age and psychosocial factors. For clerks, the corresponding figures were 51\% and $44 \%$, respectively. Therefore, the risk of low-back pain for these two categories compared with managers was no longer significantly increased.

Most confidence intervals for the percentages of change, given by bootstrap, were large. However, the lower limits of the confidence intervals for percentages of change associated with adjustment on biomechanical strains were $\geq 0.25$ (depending on the models compared) for blue-collar workers. For clerks, the corresponding values were $>0.12$. The confidence intervals suggested that taking into account decision latitude and social support did not change significantly the PR.

\section{Discussion}

This study, based on a longitudinal design, showed occupational class disparities for persistent or recurrent low-back pain among men in the GAZEL cohort. Occupational strains played an important role in these inequalities. Physical factors accounted for the greatest portion of the observed disparities, even when the role of psychosocial factors was also taken into account.

Before discussing these results, some limitations of the study must be considered. First, we could not study the relations between low-back pain and socioeconomic position among women because there were not enough of them in the GAZEL cohort. Therefore only men could be included.

The final response rate was rather low, especially because only $67 \%$ of the men who completed the 1996 
Table 2. Prevalence ratio of low-back pain for $>30$ days according to socioeconomic status, occupational strains and contribution of these strains to occupational class disparities for low-back pain. ( $95 \% \mathrm{Cl}=95 \%$ confidence interval; $\mathrm{OR}=$ odds ratio)

\begin{tabular}{|c|c|c|c|c|c|c|c|c|}
\hline & \multirow{2}{*}{$\begin{array}{l}\text { Prevalence- } \\
\text { ratio a, b }\end{array}$} & \multirow[t]{2}{*}{$95 \% \mathrm{Cl}$} & \multicolumn{2}{|c|}{ Model Ac } & \multicolumn{2}{|c|}{ Model Bd } & \multicolumn{2}{|c|}{ Model Ce } \\
\hline & & & $\mathrm{OR}$ & $95 \% \mathrm{Cl}$ & $\mathrm{OR}$ & $95 \% \mathrm{Cl}$ & $\mathrm{OR}$ & $95 \% \mathrm{Cl}$ \\
\hline \multicolumn{9}{|l|}{ Socioeconomic position } \\
\hline Managers & 1 & . & 1 & . & 1 & . & 1 & . \\
\hline Intermediate grade & 1.03 & $0.72-1.48$ & 0.85 & $0.57-1.25$ & 0.99 & $0.68-1.43$ & 0.82 & $0.55-1.22$ \\
\hline Clerks & 2.36 & $1.41-3.95$ & 1.74 & $1.01-3.00$ & 2.20 & $1.28-3.78$ & 1.66 & $0.95-2.92$ \\
\hline \multicolumn{9}{|l|}{ Change in prevalence ratio } \\
\hline Reference=age adjusted & . & . & 0.45 & $0.16-0.98$ & 0.11 & $-0.11-0.45$ & 0.51 & $0.17-1.11$ \\
\hline Reference $=$ model $\mathrm{A}$ & . & . & . & . & . & . & 0.11 & $-0.33-1.23$ \\
\hline Reference=model B & . & . & . & . & . & . & 0.44 & $0.12-1.11$ \\
\hline Blue-collar workers & 1.92 & $1.36-2.70$ & 1.25 & $0.80-1.95$ & 1.81 & $1.27-2.60$ & 1.21 & $0.77-1.90$ \\
\hline \multicolumn{9}{|l|}{ Change in prevalence ratio } \\
\hline Reference=age-adjusted & . & . & 0.73 & $0.27-1.36$ & 0.11 & $-0.11-0.40$ & 0.77 & $0.31-1.49$ \\
\hline Reference=model $\mathrm{A}$ & . & . & . & . & . & . & 0.16 & $-0.59-8.93$ \\
\hline Reference=model $\mathrm{B}$ & . & . & . & . & . & . & 0.74 & $0.25-1.60$ \\
\hline \multicolumn{9}{|l|}{ Occupational strain } \\
\hline Driving $^{\dagger}$ & 1.52 & $1.17-1.91$ & 1.02 & $0.75-1.37$ & .. & .. & 1.02 & $0.75-1.37$ \\
\hline Bending/twisting ${ }^{f}$ & 2.07 & $1.64-2.65$ & 1.84 & $1.32-2.55$ & .. & .. & 1.80 & $1.29-2.51$ \\
\hline Handling loads ${ }^{\dagger}$ & 1.70 & $1.35-2.24$ & 1.04 & $0.74-1.46$ & .. & .. & 1.04 & $0.74-1.46$ \\
\hline High psychological demand & 1.14 & $0.88-1.48$ & .. & .. & .. & .. & .. & .. \\
\hline Low decision latitude & 1.32 & $1.01-1.73$ & .. & .. & 1.11 & $0.83-1.48$ & 1.09 & $0.82-1.45$ \\
\hline Low social support & 1.26 & $0.98-1.64$ & .. & .. & 1.21 & $0.94-1.57$ & 1.18 & $0.91-1.53$ \\
\hline
\end{tabular}

a Adjusted for age.

b Prevalence ratios adjusted for age are issued from seven separated models, each one corresponding to one of the following variables: socioeconomic status (in four categories); driving (quantitative); bending/twisting (quantitative); handling loads (quantitative); psychological demand (two categories); decision latitude (two categories); social support (two categories).

c Model A: Relations between low-back pain and socioeconomic status, adjusted for age and biomechanical strains.

${ }^{a}$ Model B: Relations between low-back pain and socioeconomic status, adjusted for age, decision latitude, and social support.

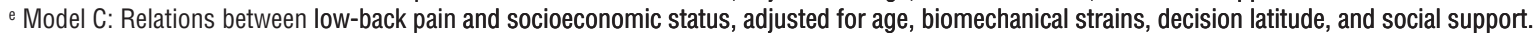

${ }^{t}$ Prevalence ratio given for 20 years of exposure.

and 2001 questionnaires responded to Karasek's Job Content Questionnaire in 1997. Most of those who did not complete this questionnaire had already retired in 1997 and thus did not answer the questions on psychosocial factors at work. The legal age for retirement is rather low in France; in addition, those who held specific jobs classified as strenuous in Electricité de France-Gaz de France were allowed to retire before the legal age for retirement. Some subjects were also excluded because they answered only some questions. We chose not to use any method to substitute missing answers so that we could have a "straight" evaluation of psychosocial factors and optimize our assessment of their contribution to the relations of interest.

A validated self-administered questionnaire was used to assess these psychosocial factors (32). Physical exposure was also self-assessed in this study (39). Moreover the assessment was retrospective, as it concerned the cumulative duration of exposure to biomechanical strains throughout the subjects' working lives. Respondents' answers appeared consistent with information they reported in earlier questionnaires. Nonetheless, we cannot rule out the possibility of recall bias. If such bias was present, it should not have been differential, since the information on low-back pain was collected five years later, in 2001.

The classification of socioeconomic position into four main categories was based on objective information provided by the company in 1989 and not self-assessment. However, as information on low-back pain and exposure at work were self-reported we cannot rule out the possibility of biases related to negative affectivity (19). Nevertheless, we expect them to be minimal, as information was collected at different points in time.

We chose to consider a definition of low-back pain independent of care seeking or sick leave, both of which are consequences that could be related, per se, to the occupational exposures studied. By selecting only disorders that lasted $>30$ days, we focused on low-back pain associated with high social and economic costs.

The data and the study design appeared appropriate for the discussion of hypotheses concerning "pathways" for inequalities in low-back pain. As low-back pain is rather common, statistical analyses based on Cox models were preferred to the computation of odd ratios (33).

The results suggest that occupational factors play an 
important role in occupational class disparities in lowback pain. Other factors might have played a role. Obesity is more prevalent in lower socioeconomic classes and also a risk factor for low-back pain. Smoking has been associated with low-back pain in some studies and is also more prevalent in less-favored socioeconomic situations. In our population, smoking was not associated with low-back pain, and taking the body mass index into account did not change the contribution of occupational factors to the relation studied.

Psychosocial factors at work played a modest role in the relation between low-back pain and socioeconomic position. Each psychosocial dimension was studied separately, but we verified that combining these dimensions did not change our findings. Most of the study population had retired by 2001 and, thus, were no longer exposed to these working conditions. One explanation for the limited role of psychosocial factors in our results may be that the effects of these factors do not persist several years after exposure has ceased. We nonetheless noted that, in the literature, evidence is limited for the specific role of these factors in low-back pain; conflicting results are observed and some studies suffer from methodological shortcomings $(22,23)$. The modest role found for psychosocial factors at work in our study is, therefore, consistent with this literature.

Physical exposures at work played the greatest role in the relation between low-back pain and socioeconomic position. The contribution of these factors could also be analyzed for all the men for whom information on these exposures was available (the 2218 who completed the 1996 and 2001 questionnaires, irrespective of their participation in the 1997 questionnaire on psychosocial factors). Very similar results were observed for the relation between low-back pain, socioeconomic position and biomechanical factors at work, which validated our findings on biomechanical strains.

It might appear surprising that biomechanical strains had such important a role in explaining the excess risk of low-back pain among clerks in this population. This may be related in part to the fact that some of these clerks have also been blue-collar workers at some point in time; male clerks in Electricité de France-Gaz de France comprise workers with disabilities, no longer able to perform physically demanding tasks. Confidence intervals for percentages of change in PR show that the results for this group are imprecise, due to the small size of the group.

Generally speaking, confidence intervals for PR changes were wide. In most similar studies, these confidence intervals are not given, mainly because there is no standard statistical procedure for their calculation. It is probable that these confidence intervals are often large, especially if the samples are of limited size. The formula for PR change suggests also that this quantity could be imprecise if the denominator is $\approx 0$, which is the case if the partly adjusted $P R$ is $\approx 1$. Despite a lack of precision, in this population, biomechanical strains explained a substantial part of the observed socioeconomic inequalities. The results based on the comparison between models $\mathrm{C}$ and $\mathrm{B}$ can be considered as the best measure, since they estimate the contribution of biomechanical strains in addition to psychosocial factors. However, these results were rather similar to those comparing models $\mathrm{C}$ and $\mathrm{A}$.

For a better understanding of potential mechanisms leading to social inequalities in health, models are increasingly being compared (36). However, questions about causal mechanisms behind social inequalities are complex, and methods must also take into account knowledge from other fields of epidemiology.

Studies dealing with the contribution of occupational factors to socioeconomic disparities in low-back pain are scarce. The population we studied here could be considered specific, since it came from a single company with a civil servant-like status. Our results appear, nonetheless, consistent with those collected from other populations. For example, results on the same topic from the general population in France are in agreement with our findings (24); occupational disparities for low-back pain experienced by working people in Oslo were also found to be substantially mediated by working conditions and mainly physical demand (19).

\section{Concluding remarks}

In this study, biomechanical factors mainly accounted for socioeconomic disparities in persistent or recurrent low-back pain. Our findings showed that reducing occupational strains, particularly biomechanical ones, could substantially help to reduce socioeconomic disparities in persistent or recurrent low-back pain, mainly for blue-collar workers.

\section{Acknowledgements}

We thank S Sabia for her help with the statistical calculations.

\section{References}

1. Heistaro S, Vartiainen E, Heliövaara M, Puska P. Trends of back pain in eastern Finland, 1972-1992, in relation to socioeconomic status and behavioral risk factors. Am J Epidemiol. 1998;148:671-82.

2. Leino-Arjas P, Hänninen K, Puska P. Socioeconomic 
variation in back and joint pain in Finland . Eur J Epidemiol. 1998;14:79-87.

3. Dionne CE, Von Korff M, Koepsell TD, Deyo RA, Barlow WE, Checkoway H. Formal education and back pain: a review. J Epidemiol Community Health. 2001;55:455-68.

4. Kaila-Kangas L, Keskimäki I, Notkola V, Mutanen P, Riihimäki H, Leino-Arjas P. How consistently distributed are the socioeconomic differences in severe back morbidity by age and gender?: a population based study of hospitalisation among Finnish employees. Occup Environ Med. 2006;63:278-82.

5. Lundberg I, Hemmingsson T, Hogstedt $\mathrm{C}$, editors. Work and social inequalities in health in Europe. Brussels, Bern, Berlin, Frankfurt am Main, New York, Oxford, Wien: Peter Lang Publishing; 2007. Work \& Society, volume 58, p 11-33.

6. Kistensen P. Inequalities in health social causation and the role of occupation [editorial]. Scand J Work Environ Health. 2008;34(4):235-8.

7. Schrijvers CT, van de Mheen HD, Stronks K, Mackenbach JP. Socioeconomic inequalities in health in the working population: the contribution of working conditions. Int J Epidemiol. 1998;27:1011-8.

8. Warren JR, Hoonakker P, Carayon P, Brand J. Job characteristics as mediators in SES-health relationships. Soc Sci Med. 2004;59:1367-78.

9. Borrell C, Muntaner C, Benach J, Artazcoz L. Social class and self-reported health status among men and women: what is the role of work organisation, household material standards and household labour? Soc Sci Med. 2004;58 :1869-87.

10. Hemström O. Health inequalities by wage income in Sweden: the role of work environment. Soc Sci Med. 2005;61:637-47.

11. Rahkonen O, Laaksonen M, Martikainen P, Roos E, Lahelma E. Job control, job demands, or social class?: the impact of working conditions on the relation between social class and health. J Epidemiol Community Health. 2006;60:50-4.

12. Lundberg I, Hemmingsson T, Hogstedt C, editors. Work and social inequalities in health in Europe. Brussels, Bern, Berlin, Frankfurt am Main, New York, Oxford, Wien: Peter Lang Publishing; 2007. Work \& Society, volume 58, p 79-138.

13. Niedhammer I, Chastang JF, David S, Kelleher C. The contribution of occupational factors to social inequalities in health: findings from the national French SUMER survey. Soc Sci Med. 2008;67:1870-81.

14. Borg V, Kristensen TS. Social class and self-rated health: can the gradient be explained by differences in life style or work environment? Soc Sci Med. 2000;51:1019-30.

15. Stansfeld SA, Head J, Fuhrer R, Wardle J, Cattell V. Social inequalities in depressive symptoms and physical functioning in the Whitehall II study: exploring a common cause explanation. J Epidemiol Community Health. 2003;57:361-7.

16. Marmot MG, Bosma H, Hemingway H, Brunner E, Stansfeld S. Contribution of job control and other risk factors to social variations in coronary heart disease incidence. Lancet. 1997;350:235-9.

17. Aittomäki A, Lahelma E, Rahkonen O, Leino-Arjas $\mathrm{P}$, Martikainen P. The contribution of musculoskeletal disorders and physical workload to socioeconomic inequalities in health. Eur J Public Health. 2007;17:145-50.

18. Melchior M, Roquelaure Y, Evanoff B, Chastang JF, Ha C, Imbernon $\mathrm{E}$, et al. Why are manual workers at high risk of upper limb disorders?: the role of physical work factors in a random sample of workers in France (the Pays de la Loire study). Occup Environ Med. 2006;63:754-61.

19. Mehlum IS, Kristensen P, Kjuus H, Wergeland E. Are occupational factors important determinants of socioeconomic inequalities in musculoskeletal pain? Scand J Work Environ Health. 2008;34(4):250-9.

20. Burdorf A, Sorock G. Positive and negative evidence of risk factors for back disorders [review]. Scand J work Environ Health. 1997;23(4):243-56.

21. Hoogendoorn WE, Bongers PM, de Vet HC, Douwes M, Kowes BW, Mediema MC, et al. Flexion and rotation of the trunk and lifting at work are risk factors for low-back pain: results of a prospective cohort study. Spine. 2000;25:3087-92.

22. Hartvigsen J, Lings S, Leboeuf-Yde C, Bakketeig L. Psychosocial factors at work in relation to low-back pain and consequences of low-back pain; a systematic, critical review of prospective cohort studies. Occup Environ Med. 2004;61:e2.

23. Hoogendoorn WE, van Poppel MN, Bongers PM, Koes BW, Bouter LM. Systematic review of psychosocial factors at work and private life as risk factors for back pain. Spine. 2000;25:2114-25.

24. Leclerc A, Gourmelen J, Chastang JF, Plouvier S, Niedhammer I, Lanoë JL. Level of education and back pain in France: the role of demographic, lifestyle and physical work factors. Int Arch Occup Environ Health. 2009;82:643-52.

25. Latza U, Kohlmann $T$, Deck R, Raspe H. Influence of occupational factors on the relation between socioeconomic status and self-reported back pain in a population-based sample of German adults with back pain. Spine. 2000;25:1390-7.

26. Goldberg M, Chastang JF, Leclerc A, Zins M, Bonenfant S, Bugel I, et al. Socioeconomic, demographic, occupational, and health factors associated with participation in a longterm epidemiologic survey: a prospective study of the French GAZEL cohort and its target population. Am J Epidemiol. 2001;154:373-84.

27. Goldberg M, Chastang JF, Zins, M, Niedhammer I, Leclerc A. Health problems were the strongest predictors of attrition during the follow-up of the GAZEL cohort. J Clin Epidemiol. 2006;59:1213-21.

28. Tubach F, Leclerc A, Landre MF, Pietri-Taleb F. Risk factors for sick leave due to low back pain: a prospective study. J Occup Environ Med. 2002;44:451-8.

29. Kuorinka I, Jonsson B, Kilbom A, Vinterberg H, BieringSørensen F, Andersson G, et al. Standardised Nordic questionnaires for the analysis of musculoskeletal symptoms. Appl Ergon. 1987;18:233-7.

30. Griffith LE, Hogg-Johnson S, Cole DC, Krause N, Hayden J, Burdorf A, et al. Low-back pain definitions in occupational studies were categorized for a meta-analysis using Delphi consensus methods. J Clin Epidemiol. 2007;60:625-33. 
31. Karasek R. Job demands, job decision latitude and mental strain: implications for job redesign. Adm Sci Q.1979;24:285306.

32. Larocque B, Brisson C, Blanchette C. Cohérence interne, validité factorielle et validité discriminante de la traduction française des échelles de demande psychologique et de latitude décisionnelle du Job Content Questionnaire de Karasek [Internal consistency, factorial validity and discriminant validity of the French version of the psychological demands and decision latitude scales of the Karasek "Job Content Questionnaire"]. Rev Epidemiol Sante Publique. 1998;46:371-81.

33. Axelson O. Some recent developments in occupational epidemiology [review]. Scand J Work Environ Health. 1994;20 special issue:9-18.

34. Barros AJD, Hirakata VN. Alternatives for logistic regression in cross-sectional studies: an empirical comparison of models that directly estimate the prevalence ratio. BMC Med Res Methodol. 2003;3:21.

35. Plouvier S, Renahy E, Chastang JF, Bonenfant S, Leclerc A.
Biomechanical strains and low-back disorders: quantifying the effects of the number of years of exposure on various types of pain. Occup Environ Med. 2008;65:268-74.

36. Hafeman DM, Schwartz S. Opening the black box: a motivation for the assessment of mediation. Int $\mathrm{J}$ Epidemiol. 2009;38:838-45.

37. Virtanen P, Siukula A, Luukkaala T, Savinainen M, Arola $\mathrm{H}$, Nygård $\mathrm{C}-\mathrm{H}$, et al. Sick leave in four categories - do characteristics of employees and work conditions explain differences in sickness absences between workplaces? Scand J Work Environ Health. 2008;34(4):260-6.

38. Efron B, Tibshirani RJ. An introduction to the bootstrap. New York (NY): Chapman \& Hall; 1993.

39. Stock SR, Fernandes R, Delisle A, Vézina N. Reproducibility and validity of workers' self-reports of physical work demands [review]. Scand J Work Environ Health. 2005;31(6):409-37.

Received for publication: 6 April 2009 